\title{
Nutritional and Healthy Benefits of Fruits
}

\author{
Waleed Fouad Abobatta* \\ Horticulture Research Institute- Agriculture Research Center, Egypt \\ *Corresponding author: Waleed Fouad Abobatta- Horticulture Research Institute- Agriculture Research Center- Giza, \\ Egypt
}

\section{ARTICLE INFO}

Received: 㓞 November 11, 2021

Published: 幽 November 24, 2021

Citation: Waleed Fouad Abobatta. Nutritional and Healthy Benefits of Fruits. Biomed J Sci \& Tech Res 40(2)-2021. BJSTR. MS.ID.006412.

Keywords: Fruits; Nuts; Vitamins; Carotenoids; Flavonoids

\begin{abstract}
Fruits, nuts, dried fruits, and fruit juice are important components for a balanced diet; it is essential part of the staple diet. Due to their benefits for healthy body and preventive effect of numerous diseases. Fruits contain different phytochemicals, dietary fiber, protein, carbohydrates, vitamins, carotenoids, flavonoids, and other components. Furthermore, nuts and dry fruits considered a precious source of energy, antioxidants components, higher vitamins content, source for numerous minerals. Daily fruits consume particularly, Date fruits, citrus fruit, pomegranate, and Cranberries, provide several advantages for the body and different metabolic processes in human body. It is play an important role in the management of diabetes mellitus, delaying infection with chronic diseases, enhancing performance of different systems and physiological processing, reducing harmful effects on human health, in addition, it is provide nutritional ingredients such as vitamins, dietary fiber, carbohydrates, minerals ...etc. Higher content of fruits particularly antioxidants plays an important role in altering the metabolic processing and detoxification of different diseases particularly carcinogens and reducing the growth of tumor cells. In addition to the effects as potent antioxidants and anti-inflammatory agents, which reduce risks of the pathogenesis of cardiovascular disease by counteracting oxidative and inflammation hazards. Furthermore, there are important roles for bioactive components contents of fruits in keeping heart-healthy, preventing cardio-metabolic and non-communicable diseases through different mechanisms.
\end{abstract}

\section{Introduction}

A wide variety of fruits and other plant-based foods provide a wide range of bioactive ingredients like phytochemicals, vitamins, minerals, and fibers Samtiya, et al. [1]. Fruit considered an essential component of the human diet since ancient times, in addition, Date fruits in some regions like desert areas it has been a part of the daily diet, whereas the community depended mainly on eating dates as the main component of their daily meals Vayalil [2]. Furthermore, fruits are used within religious rituals in different regions of the world, Furthermore, fruits are used within religious rituals in different regions of the world. In addition, fruits are used for medical purposes as a part of traditional medicine in different ancient civilizations. For example, Date is one of the oldest fruits that have been used for medicinal purposes due to their unique properties either alone or in combination with other plants Vayalil
[2]. Fresh fruits represent valuable resources of numerous vitamins like vitamin $\mathrm{C}$, vitamin $\mathrm{A}$, vitamin $\mathrm{B} 6$, vitamin $\mathrm{E}$, etc. In addition, dry fruits and nuts are considered a good source of important fiber, calories, amino acids, and other important components. Fruits contain important antioxidants that play an important role in altering the metabolic processing and detoxification of different diseases particularly carcinogens and Furthermore, fruits are used within religious rituals in different regions of the world.

It is well documented that, regular consumption of fruits, nuts, and vegetables would alleviate the risk of cardiovascular disease (CVD). Furthermore, there are numerous benefits of fruit consumption in delaying and reducing different health difficulties $\mathrm{Hu}$ [4]. Regular fruit consumption as a part of healthy food is considered a proper strategy for controlling various diseases like 
diabetes and other chronic diseases Lockyer, et al. [5,6]. This work discusses the importance of fruit-eating as the main component of the daily diet, which is considered one of the main vital ways to maintain and prevent different health complications.

\section{Advantages of Regular Consume of Fruit}

Fruits are crucial components for a balanced diet. It has beneficial effects on human health and preventing of different diseases. The health effects of fruits attribute to the combination of phytochemicals, fiber, vitamins, and other nutrients, in addition to the sole effects as potent antioxidants and anti-inflammatory agents, thereby reducing risks of the pathogenesis of CVD by counteracting oxidative and inflammation hazards. Therefore, fruits are considered very important to maintain public health Wootton-Beard [7,8].

Fruits provide numerous advantages for the human body that include:

1. Fruit eating represent a potential hope to limit harmful effects on human health.

2. Fruits affect the performance of different systems in the body and different metabolic and physiological processing.

3. Delaying infection with chronic diseases

4. Played a vital role in the management of diabetes mellitus

5. One of the essential components of the staple diet.

6. Provide nutritional ingredients such as vitamins, dietary fiber, carbohydrates, minerals ...etc.

\section{Health Benefits of Some Fruits}

\section{a. Date Fruits}

Date fruits (Phonix dactylifera) are highly nutritious and may have several potential health benefits. Due to phytochemical composition, nutritional values, and potential health benefits date fruit is considered a medicinal food for different diseases inflicting human beings, due to phenolic compounds that are considered the main components that work as antioxidants in date fruits Younas, et al. $[9,10]$.

\section{b. Pomegranate}

Pomegranate (Punica granatum L.) is one of the valuable fruits that polyphenol-rich fruit with a high antioxidant capacity compared to other fruit such as cranberry, grapes, or even citrus species Fahmy, et al. [11]. In addition, pomegranate juice has numerous health effects such as antiatherogenic, antioxidant, antihypertensive, and anti-inflammatory effects Basu [8]. Therefore, daily consumption of pomegranate juice increased heart-healthy. Antioxidant components in Pomegranate juice reach three-fold than that in green tea or red wine, due to the higher ability as freeradical scavenging and reducing iron oxidative Stockton [12].

\section{c. Cranberries}

Regular consumption of Cranberries (Vaccinium macrocarpon) is very important in the maintenance of health and in preventing CVD and infections in the urinary tract Ruel [13]. Fresh, dried fruits and juice of Cranberries contain various components particularly flavonoids like flavonols myricetin and quercetin, which are considered a significant source of antioxidants and antiinflammatory Skrovankova [14]. Therefore, these substances act as a potent antioxidant, which could prevent and reduce infecting of the urinary tract, through its inhibitory effect on the bacterial activity that causes infections in the urinary tract Nowack [15].

\section{d. Citrus Fruit}

Citrus fruits and juice contain various components that include calcium, potassium, phosphorous, vitamin C, Vitamins B, dietary fibers,...etc., which are beneficial for the human body, also, there are various active compounds extracted from citrus used as medicines for heart diseases, and in treatments of hypertension Abobatta [16]. Citrus products have different healthy properties such as anticancer, inflammation, antiviral, antibacterial, and antifungal activity. Furthermore, the enzymes content in citrus juice represented a natural medical component for obesity treatments. In addition to a wide range of various proteins, that reduces fats in the human body Barreca, et al. [17].

\section{Dried Fruits and Nuts}

Dried fruits and nuts are an important part of the daily diet for several people in different regions worldwide particularly in arid and semi-arid regions like sub-Saharan since ancient times Shumsky, et al. [18] and in the north of Europe. Dried fruits and Nuts are considered important foods due to their higher nutritional values, and provide healthy bioactive substances for the human body. In addition, it provides a source of energy, higher contents of antioxidants, and minerals. There are different dried fruits like Date fruits (Phonix dactylifera), raisins (Vitis vinifera), goji fruits (Lycium barbarum), and cranberries (Vaccinium macrocarpon and oxycoccus) Jeszka-Skowron, et al. [19]. Currently, there is more attention to the consumption of nuts and dried fruits as a part of the daily diet due to health benefits and their desired flavor. In addition, it provides the human body with requirements for nutrients, bioactive compounds, and antioxidants Chang, et al. [20]. Nuts are characterized by their high content of fats (especially unsaturated fatty acids), polyphenols, and phytosterols, in addition to protein, vegetable fiber, and many useful substances such as folic acid and vitamin $\mathrm{E}$, in addition to their content of sufficient amounts of selenium, magnesium and many other minerals.

Therefore, including nuts such as almonds, walnuts, hazelnuts, cashews, pistachios, peanuts, Brazil nuts, macadamia nuts, and pine nuts in the daily diet provides sufficient amounts of energy for the body. In addition to, numerous beneficial effects such as regulating 
the body's immunity, raising body resistance for infection with many diseases.

\section{Advantage of Nuts and Dried Fruits}

The bioactive components contents of dried fruits and Nuts play a significant role in preventing cardio-metabolic and noncommunicable diseases through different mechanisms Alasalvar, et al. [21].

There are different health benefits of nuts and dried fruits for the human body that include:

a) Source of energy b) Antioxidants components

c) Higher vitamins content

d) Source for different minerals like $\mathrm{K}, \mathrm{Mn}, \mathrm{Fe}, \mathrm{Mg}$,.etc

\section{Comparison of Antioxidant Activities and Phenolic Content of Fruits}

There are heart-healthy and colorful substances of phytochemicals in fruits particularly carotenoids, and polyphenols, which have been associated with reducing risks of cardiovascular disease. There are various phytochemicals in fruits, whereas the significant groups can be classified as shown in (Figure 1).

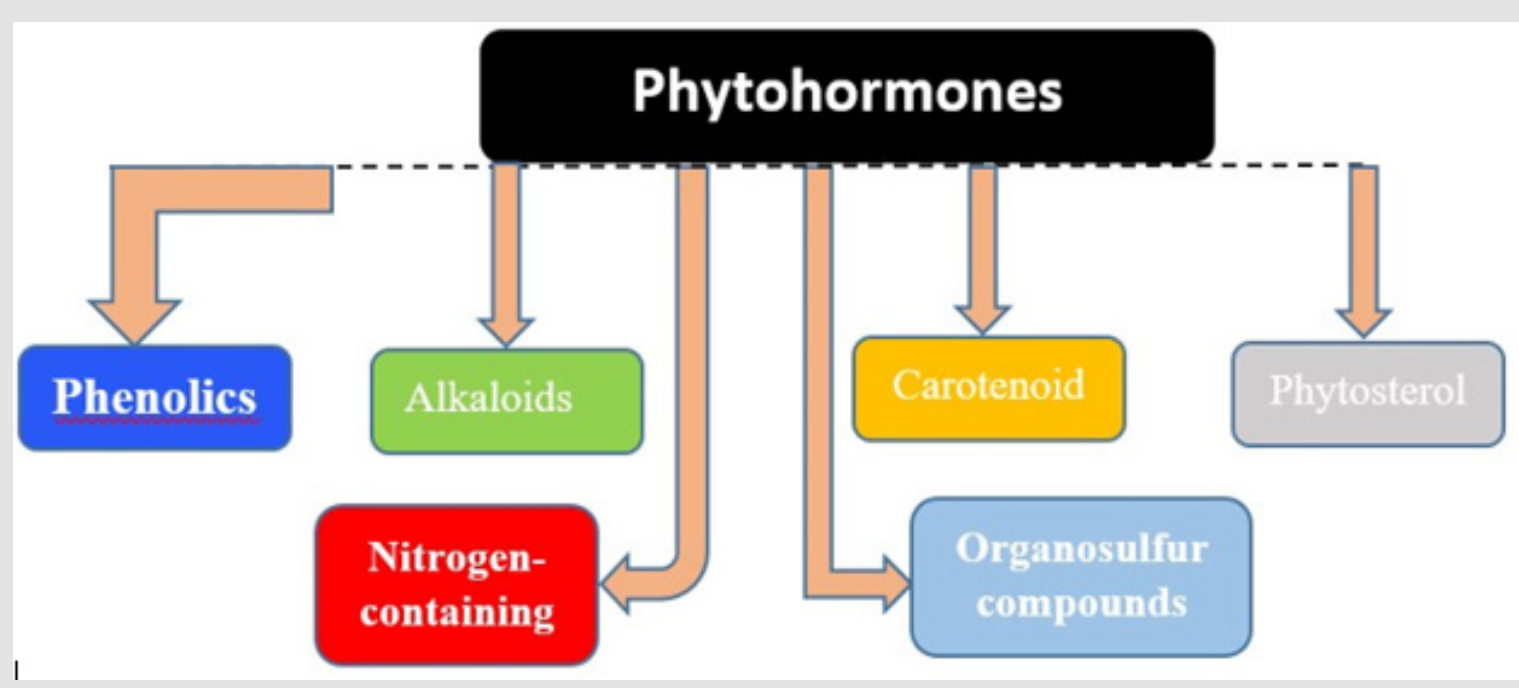

Figure 1: Main groups of phytohormones in fruits.

\section{a) Carotenoids}

There is a beneficial influence of the consumption of carotenoidrich fruits (Yellow-fleshed fruits) like orange, grapefruit, Apricot, Mango, persimmon, Avocado, Papaya ...etc. in the diet on reducing systemic inflammation disease. In addition, eating carotenoid-rich fruits affect positively on inflammation status through increasing plasma concentrations Jahns, et al. [22]. For instance, beta-carotene is an energetic antioxidant and is considered a preventive factor against some cancer diseases and aging Fiedor [23]. Furthermore, carotenoids play important role in protecting optical density, maintenance a clear vision, and keeping the eye healthy. Clinical studies Mitra, et al. [24-26] are well establishing different benefits of carotenoids particularly lutein and zeaxanthin compounds to maintain and protect eyes as follow:

1. Protect the macula from blue light hazards.

2. Enhancing visual acuity.
3. Reducing the harmful effects of free radicals.

4. Minimizing age-related degeneration (AMD) of eye health.

5. Reducing cataracts disease.

b) Phenolics

Fruit is an important source of dietary phenolics. Cranberry, wild blueberry and blackberry fruits contain the highest percentage of total phenolic, while apple fruits contain 33\% of phenolic compounds, followed by pomegranate, blueberries, plums, strawberries, and red grapes Manach, et al. [27]. Polyphenols contain numerous compounds like flavonoids, resveratrol, ellagitannins, isothiocyanates, and organosulfur.

\section{c) Flavonoids}

The beneficial impact of fruits in reducing cardiovascular diseases could be to their higher content of flavonoids, which play important role in improving cardiovascular health Viuda-Martos $[28,29]$. 


\section{Conclusion}

Fruits represent a vital source of phytochemicals, dietary fiber, protein, carbohydrates, vitamins, carotenoids, flavonoids, and other components. Therefore, daily consumption of fruits, nuts, dried fruits, and fruit juice provide important components for body health. There are different kinds of fruits such as Date fruits, oranges, grapefruits, pomegranate, Cranberries, nuts, and dried fruits that must be an essential part of the staple diet. There are important roles of daily eating fruits like management of diabetes mellitus, delaying infection with chronic diseases, altering different metabolic processes, improving the performance of various systems and physiological processing, decreasing hazard effects on the human body, in addition, it provides nutritional ingredients such as vitamins, dietary fiber, carbohydrates, minerals ...etc. Fruits have beneficial effects as potent antioxidants and anti-inflammatory agents that alleviate risks of the pathogenesis of the cardiovascular disease, reducing infection of non-communicable diseases.

\section{References}

1. Samtiya M, Aluko RE, Dhewa T, Moreno Rojas JM (2021) Potential Health Benefits of Plant Food-Derived Bioactive Components: An Overview. Foods 10(4): 839.

2. Vayalil PK (2012) Date fruits (Phoenix dactylifera Linn): An emerging medicinal food. Critical reviews in food science and nutrition 52(3): 249-271.

3. Al-Yahyai R, Khan MM (2015) Date palm status and perspective in Oman In Date palm genetic resources and utilization. Springer, Dordrecht, pp. 207-240.

4. Hu FB (2013) Resolved: There is sufficient scientific evidence that decreasing sugar-sweetened beverage consumption will reduce the prevalence of obesity and obesity-related diseases. Obesity reviews 14(8): 606-619.

5. Lockyer S, Spiro A, Stanner S (2016) Dietary fibre and the prevention of chronic disease-should health professionals be doing more to raise awareness?. Nutrition Bulletin 41(3): 214-231.

6. Chandrasekaran M, Bahkali AH (2013) Valorization of date palm (Phoenix dactylifera) fruit processing by-products and wastes using bioprocess technology-Review. Saudi journal of biological sciences 20(2): 105-120?

7. Wootton Beard PC, Ryan L (2011) Improving public health?: The role of antioxidant-rich fruit and vegetable beverages. Food Research International 44(10): 3135-3148.

8. Basu A, Penugonda K (2009) Pomegranate juice: A heart-healthy fruit juice. Nutrition reviews 67(1): 49-56.

9. Younas A, Naqvi SA, Khan MR, Shabbir MA, Jatoi MA, et al. (2020) Functional food and nutra-pharmaceutical perspectives of date (Phoenix dactylifera L.) fruit. Journal of food biochemistry 44(9): e13332.

10. Taouda H, Chabir R, Errachidi F, Aarab L (2014) Comparison of antioxidant activities and phenolic content of Moroccan date fruits. Int ] Innov Res Sci Eng Technol 3: 16120-16126.

11. Fahmy H, Hegazi N, El-Shamy S, Farag MA (2020) Pomegranate juice as a functional food: A comprehensive review of its polyphenols, therapeutic merits, and recent patents. Food \& Function 11(7): 5768-5781.
12. Stockton A (2019) The effect of pomegranate on anthropometric, biochemical, cognitive and satiety indicators of risk factors for noncommunicable diseases (Doctoral dissertation, Queen Margaret University, Edinburgh).

13. Ruel G, Couillard C (2007) Evidences of the cardio protective potential of fruits: The case of cranberries. Molecular Nutrition \& Food Research 51(6): 692-701.

14. Skrovankova S, Sumczynski D, Mlcek J, Jurikova T, Sochor J (2015) Bioactive compounds and antioxidant activity in different types of berries. International journal of molecular sciences 16(10): 2467324706.

15. Nowack R, Birck R (2015) Cranberry products in the prevention of urinary tract infections: Examining the evidence. Botanics: Targets and Therapy 5: 45-54.

16. Abobatta WF (2019) Nutritional Benefits of Citrus Fruits. Am J Biomed Sci \& Res 3(4): 303-306.

17. Barreca D, Gattuso G, Bellocco E, Calderaro A, Trombetta D, et al. (2017) Flavanones: Citrus phytochemical with health-promoting properties. BioFactors 43(4): 495-506.

18. Shumsky SA, Hickey GM, Pelletier B, Johns T (2014) Understanding the contribution of wild edible plants to rural social-ecological resilience in semi-arid Kenya. Ecology and Society 19(4).

19. Jeszka Skowron M, Zgoła Grześkowiak A, Stanisz E, Waśkiewicz A (2017) Potential health benefits and quality of dried fruits: Goji fruits, cranberries and raisins. Food chemistry 221: 228-236.

20. Chang SK, Alasalvar C, Shahidi F (2016) Review of dried fruits: Phytochemicals, antioxidant efficacies, and health benefits. Journal of Functional Foods 21: 113-132.

21. Alasalvar C, Salvadó JS, Ros E (2020) Bioactives and health benefits of nuts and dried fruits. Food Chemistry 314: 126192.

22. Jahns L, Conrad Z, Johnson LK, Whigham LD, Wu D, et al. (2018) A diet high in carotenoid-rich vegetables and fruits favorably impacts inflammation status by increasing plasma concentrations of IFN- $\alpha 2$ and decreasing MIP- $1 \beta$ and TNF- $\alpha$ in healthy individuals during a controlled feeding trial. Nutrition Research 52: 98-104.

23. Fiedor J, Burda K (2014) Potential role of carotenoids as antioxidants in human health and disease. Nutrients 6(2): 466-488.

24. Mitra S, Rauf A, Tareq AM, Jahan S, Emran TB, et al. (2021) Potential health benefits of carotenoid lutein: An updated review. Food and Chemical Toxicology, pp. 112328.

25. Bernstein PS, Li B, Vachali PP, Gorusupudi A, Shyam R, et al. (2016) Lutein, zeaxanthin, and meso-zeaxanthin: The basic and clinical science underlying carotenoid-based nutritional interventions against ocular disease. Progress in retinal and eye research 50: 34-66.

26. Nwachukwu ID, Udenigwe CC, Aluko RE (2016) Lutein and zeaxanthin: Production technology, bioavailability, mechanisms of action, visual function, and health claim status. Trends in Food Science \& Technology 49: 74-84.

27. Manach C, Scalbert A, Morand C, Rémésy C, Jiménez L (2004) Polyphenols: Food sources and bioavailability. The American journal of clinical nutrition 79(5): 727-747.

28. Viuda Martos M, López Marcos MC, Fernández López J, Sendra E, López Vargas JH, et al. (2010) Role of fiber in cardiovascular diseases: A review. Comprehensive reviews in food science and food safety 9(2): 240-258.

29. Abobatta WF (2020) Healthy Benefits of Fruits. EC Nutrition 15(3): 0108. 
ISSN: 2574-1241

DOI: 10.26717/BJSTR.2021.40.006412

Waleed Fouad Abobatta. Biomed J Sci \& Tech Res

(c) (P) This work is licensed under Creative

Submission Link: https://biomedres.us/submit-manuscript.php

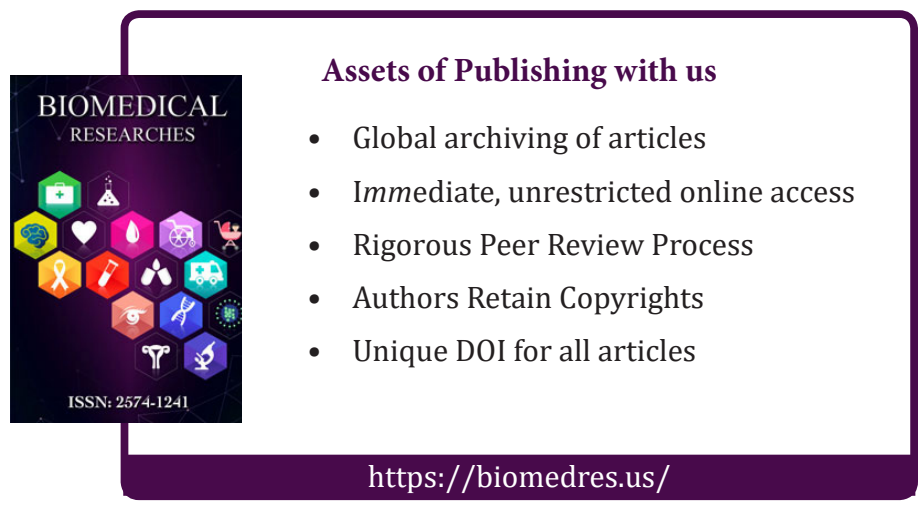

